\title{
A Comprehensive Overview of the Use of Compressible Drilling Fluids, Advantages and Challenges
}

\author{
Mahmood Amani, Mohamed Almodaris \\ Texas A\&M University at Qatar
}

\author{
*Corresponding Author: Mahmood Amani, Texas A\&M University at Qatar
}

\begin{abstract}
Air drilling is widely used because of its ability to reduce costs and time used in achieving particular outputs. The compressors used today are larger with higher volumes and pressures than before. Equipment required for air drilling are not many and they include a transfer pump, a mud pump and 1, 500 water storage barrels. The equipment's major roles are to meet the expected pressure requirements. The first step in air drilling is to unload and dry the hole by running the drill string to the bottom after which the operator starts to drill using air mist. After cleaning the hole, air misting is completed and Kelly broken off before pouring 15 gallons of soap and 3 barrels of water into the drill pipe. Air drilling is not without its challenges. The use of out-of-gauge bits can pose quite a challenge and is corrected by selecting a suitable bit. Drill pipe erosion can also be a challenge that is found in the joint metal and hard band which affects the drill's joint life time. The stability properties and stability behavior of the conventional fluid can bring about uncontrollable parameters. Cutting size and concentration are some of the uncontrollable parameters while the rate of penetration is one of the controllable parameters. Zones with low permeability, formation with lost-circulation, water shortages and formations that are water sensitive are the best sites for air drilling. The difference between mud and air drilling is the circulating medium which has an effect on deformation. There has been development in the area of air drilling over years necessitated by challenges faced in the drilling operations. A good example of technology being used today is the EM MWD, which has been used to facilitate transmissions, which has increased the depths to up 20,000 feet. Technology continues to improve as years go by.
\end{abstract}

\section{INTRODUCTION}

The idea of using air or gas as a circulating medium in drilling was introduced in early 1950's. Despite the fact that this application was initially basic, petroleum engineers had an opportunity to increase bit life and penetration rates. Since then, developments have been experienced in the techniques used in air and gas drilling. This explains why the drilling method is widely used as a method of reducing the drilling cost and time required to achieve a certain output. An increase in the cost per foot of hole created a need for the operators to come up with drilling techniques associated with better penetration rates. Through continuous improvements in air drilling practices and equipment, engineers continue to achieve notable increases in ROP over the rates obtained when a liquid medium is used. Air drilling has moved from the use of small compressors at low pressures to the use of larger compressors, volumes and pressures. Practical experience in this field made engineers to take 3000 feet per minute as the ideal annular velocity to sufficiently clean the cuttings from the well (Gilbert \& Tucker, 1968).

Additional advantages associated with the use of air include lower cost per foot, longer bit life, increased ROP, reduced damage when liquid-sensitive pay zones are involved and better control in lost circulation and cavernous areas. There are several applications that would make an operator consider underbalanced drilling with air/foam as a drilling fluid. Example application is in the case of a hard formation with low ROP and severe damage to bits. Air/foam drilling would help counter the negative effects of the hard formation resulting in faster ROP with less run to change damaged bit, if any. But main application would be in low pore pressure formation where high bottom hole pressure causes heavy losses, formation damage and potentially fracturing the formation. Figure 1 shows the fluid system type to be used based on pore pressure gradient. 


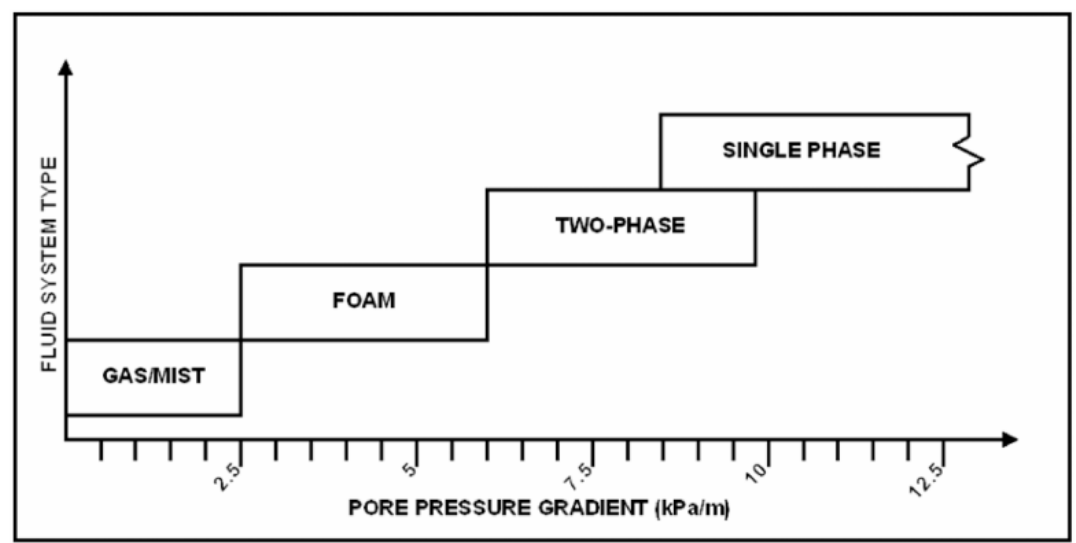

Figure1. Fluid system types for different pore pressure gradient regimes (Courtesy of Maranuk, Rodriguez, Trapasso\& Watson, 2014).

Each type has its own characteristics and with that comes an advantage and disadvantage over the other. For sake of simplicity, air/foam drilling term will be a collective term used for all four types, unless a type is specifically mentioned. Aerated liquid have a liquid to gas ratio of 46 to 54 approximately. The ideal aerated fluid combines air and fluid into stable and homogeneous foam that doesn't breakdown until it reaches the pits on surface. Fluids that exceed that ratio 4-46 to 54-96 liquid to gas are described as foam. The lighter the fluid, the more fluid velocity it requires for improving its lifting capacity. Foam has superior cuttings lifting capacity and least fluid velocity requirement out of the other underbalanced fluids. While foam isn't as environmentally friendly as air, its environmental impact is considered minimal due to its acid solubility. Air is preferred as a medium in the drilling process for its relatively lower density. Dry hard formations allow engineers to achieve the best results since the drill cuttings are obtained in form of dust. It is therefore possible to conduct immediate and continuous hydrocarbon evaluation (Copper, Hook \& Payne, 1977). Air is susceptible to water influx as the water mixes with the cuttings creating mud rings that limits hole cleaning and the potential of causing stuck pipe. In this case switching to mist or foam is suggested. Figure 2 visualizes these different fluid system types with some highlight on each type's cuttings lifting capacity. (Maranuk, Rodriguez, Trapasso\& Watson, 2014)

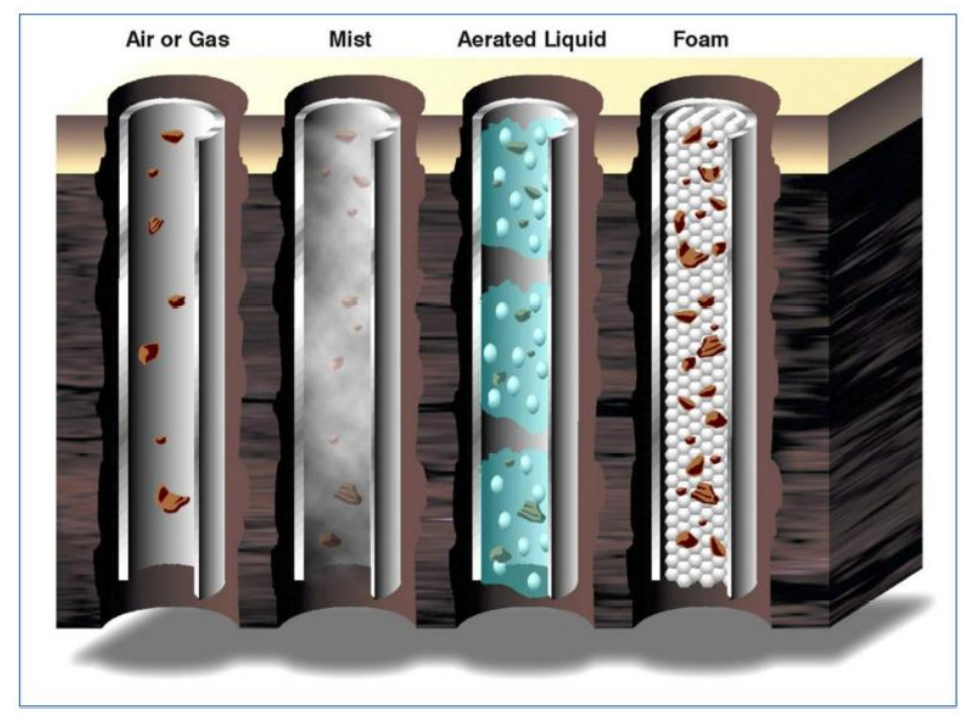

Figure1.Types of aerated fluids used for underbalanced drilling. Carrying capacity increases from left to right. Fluid velocity requirements increases from right to left (Courtesy of Manaruk, Rodriguez, Trapasso\& Watson, 2014).

\section{EQUIPMENT REQUIRED}

In air/foam drilling case, the liquid handling equipment should contain a centrifugal transfer pump, a mud pump and approximately 1,500 water storage barrels. There is also the need of a rotating drilling head that functions to maintain a steady seal around all the rotating components of the drill string. The rotating head has a rubber element whose life can be extended through lubrication. The seal created 
by the rubber element around the drill pipe prevents the drill cuttings or dust from reaching the drill floor and diverts it to the blooie line as illustrated in figure 3. Other equipments used to control blowout in air drilling are similar to the equipment used for the same purpose in mud drilling. The major requirement in this case is to meet the expected pressure requirements, which can be achieved by a double ram $\mathrm{BOP}$.

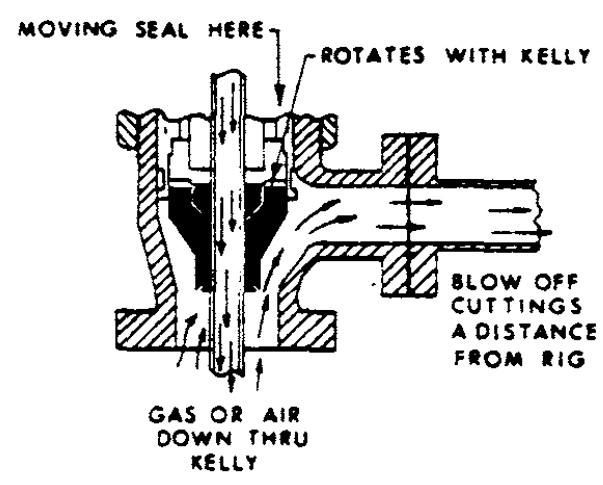

Figure3. Rotating head rubber seal around drill pipe (courtesy of Copper, Hook \& Payne, 1977)

A foam or mist unit is a necessity in air drilling to deliver approximately 30 gallons per minute. A chemical injection pump operated by air is also important for injection of the foaming agent and should have an injection rate of approximately 12.5 gallons per hour. A "blooie line" is used to carry the drill cuttings or the dust away from the rig. This should be about 175 feet in length and must be welded and well anchored. A blooie line should also be straight as any angles can result in cutting the line due surge pressure at these bends or wall-thinning from cuttings. Main components of the booie line are air jets, de-duster, sample catcher, gas detector, a hook-up for going to fluid drilling and a flare to bur off any gasses. The "de-duster" is important in reduction of drill cutting dust in the drilling process. The de-duster is installed on the blooie line and is mainly used in the cases where the wind is carrying the dust in direction of rig or an urban area. Due to the great need to constantly monitor the drilling pressure, at least two pressure recorders are fitted, one on the rig floor and second on the air compressors.

Air compressors are used to provide sufficient air volumes. The positive displacement, double acting compressor is the most common oilfield compressor. Multiple compressors can be used in a single package unit and two or more units can be placed together. Generally one air compressor volume output from $400-1200 \mathrm{cft}$ at $300-320$ psig max pressure but the vendor can provide a more detailed volume output at varying operating pressures. A booster might be necessary if drilling pressures exceed the pressure capabilities of the compressors. The booster increases pressure rating from $300-$ 1500 psig approximately. Instance where a booster would become essential if the need to switch from air drilling to mist or foam drilling arise. Mist drilling requires 30\%-40\% more air than dusting. Other instances would be in case of sloughing shale or stuck pipe where more air volume will become required (Copper, Hook \& Payne, 1977). Figure 4 simply shows how all these surface come together.

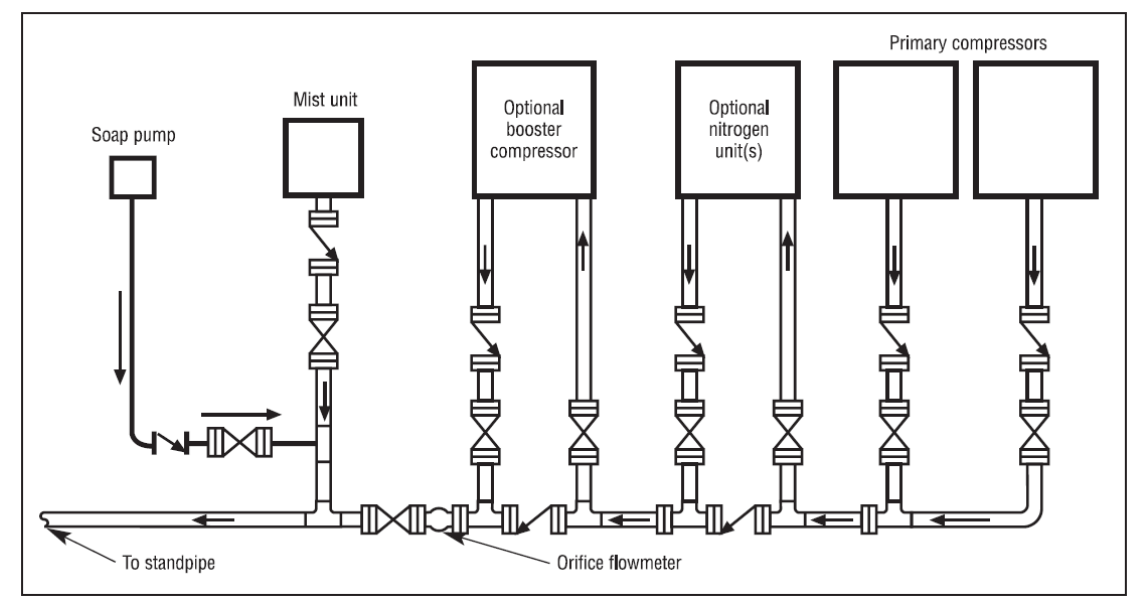

Figure4. Surface setup of air/faom drilling equipment (courtesy of Copper, Hook \& Payne, 1977) 


\section{MECHANICS OF AIR DRILLING}

To achieve actual rock removal, the rock is subjected to compressive loads associated with greater strength than that of the rock of interest. The most favorable ROP can be determined through step tests, where either WOB or rpm is changed while the other is held constant and monitoring vibrations and MSE curves. Since bit performance influences the effectiveness of the entire process, it is important to settle for a bit with the greatest gauge protection. Chips removed from the bottom are of various sizes, ranging from fine to coarse. In the case of air drilling, due to the annulus being filled only with air, the high velocity at which these cuttings collide with the hole, drill pipe, and other cuttings result in pulverizing the cuttings into dust.

In some cases, the hole will be filled with liquid fluid and needs to be unloaded and dry the hole before commencing air/foam drilling. The first step in an effort to unload and dry the hole involves running the drill string to bottom. The mud pump is started and operated as slow as possible. This can be achieved by pumping the fluid a rate of about two barrels per minute as a way of reducing the pressure of fluid frictions. A compressor and a booster are brought on line to aerate the fluid flowing down the hole. When too much pressure builds up, the pressure is slowed down to a point where the air can be mixed with the flowing fluid. Lightening of the annular fluid column decreases the standpipe pressure. This allows incorporation of higher air volume or more compressors for further lightening of the fluid column and unloading of the hole.

After the hole is unloaded, the operator should make sure that the soap injection pump and the mist pump remain in operation. This ensures that the mist provided can eliminate sloughing formations from the hole. This is the stage at which the operator is expected to start drilling using air mist by drilling between 20 to 100 feet to give room for cleanup of any sloughing hole. Stabilization of the hole is said to have been achieved if there is no sloughing observed. Drilling should be stopped at this stage and the hole blown with air mist as a way to clear all the drill cuttings. The air mist can become clean between 15 to 20 minutes after which it should appear as a white fine spray.

After the hole is clean, air misting is terminated and Kelly broken off before about 15 gallons of soap and 3 barrels of water are poured in succession into the drill pipe. The Kelly is returned to its position and the bit set on the bottom. The fact that the hole is full of air makes the water and the soap to run to the bottom. After making sure that the bit is directly on the bottom, the operator should start air at the bottom of the hole and continue for about one hour. Drilling in launched and the hole is expected to dust after approximately 10 feet of drilling height is achieved. If the operator notes that the hole dusting has not been achieved by the described procedure, it is advisable to pump additional soap slug around. If the objective is not achieved, there may be a need to perform mist drilling (Copper, Hook \& Payne, 1977).

\section{Challenges/Downhole Problems}

Air drilling isn't without its challenges and limitations. The solutions to these challenges can be simple or complex. Air/foam are less efficient in cooling and lubricating than mud. In this case, the problem can easily be solved by injecting $5-8$ gallons per hour to lubricate and cool the BHA. Mud telemetry is also not an option in the case of air/foam drilling. The use of EM MWD and RSS systems allowed for downhole communication which will be further discuss in the paper (Maranuk, Rodriguez, Trapasso\& Watson, 2014). Another challenge is potential hole enlargement due to high flow volumes and high annular velocity associated with air drilling. In this case switching from air to foam drilling will decrease the chances of enlarging the hole since foam has better lifting capacity and requires less annular velocity than air. It is worth noting that other factors play an important role in hole enlargement as well such as formation, directional plan, and drilling parameters. Thus better bit selection and optimizing drilling parameters can assist in solving the problem if switching to mist drilling wasn't an option (Gilbert \& Tucker, 1968). Sloughing of dry or wet formations and soft formations reduce air/foam drilling efficiency, although their effects are being reduced through the use of newer surface equipment(Copper, Hook \& Payne, 1977).

More problematic challenges would be water influx and air volumes. One of the problems experienced in the development of air drilling was attributed to the entry of formation water into the air-drilled holes. This decreased the drilling rates and made the process impossible in some cases. Furthermore, efforts to develop techniques and materials to prevent water influx were not very 
fruitful. Large water-bearing formations are considered the major enemy of air drilling. As a result, studies were redirected towards development of foaming agents, which were to be coupled with appropriate techniques to remove the troubling water from the holes. If the water influx isn't too severe, switching to foam drilling along with constant maintenance of the foam's gas-to-liquid ratio by mud engineer should solve the water influx. As for air volumes, it's critical to ensure sufficient air volume to clean the hole efficiently. Approximately $2200 \mathrm{cft}$ per minute is sufficient to keep the hole clean under different drilling conditions (Copper, Hook \& Payne, 1977).
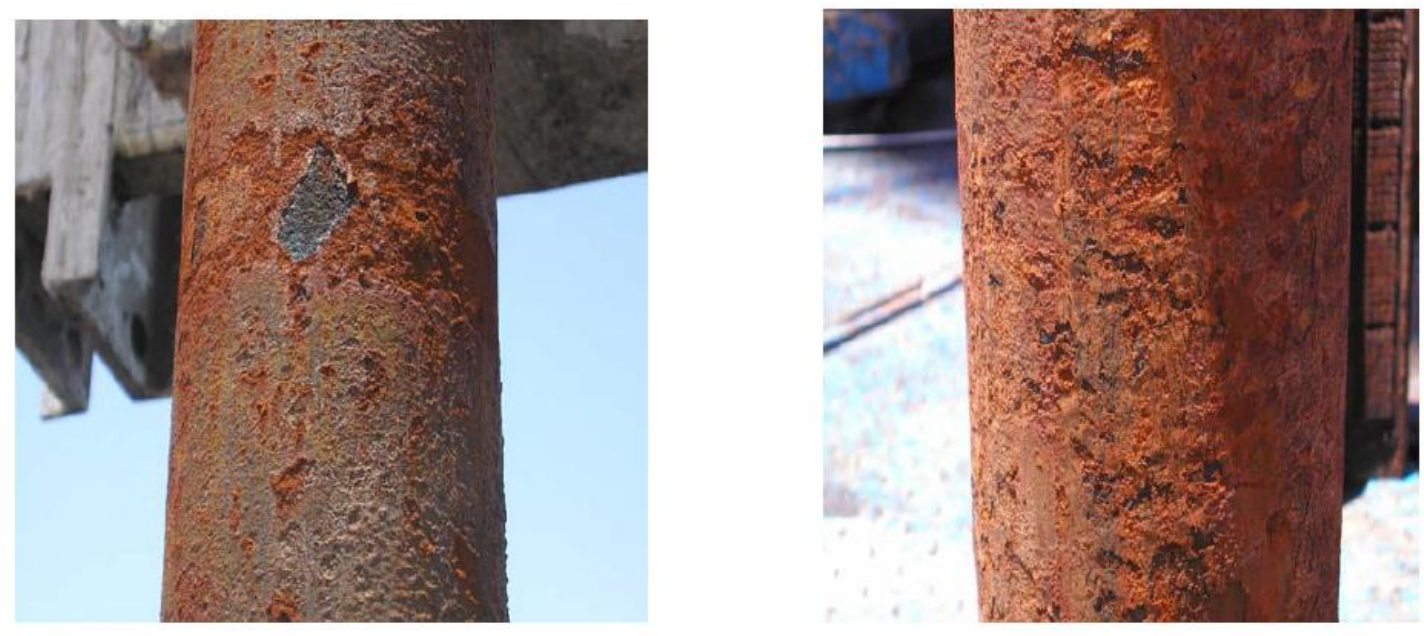

Figure5. Corrosion of S135 drill pipe (courtesy of Meng, Wan \& Chen 2005)

A major issue in the application of air as a drilling medium is corrosion of the drill pipe as show in figure 5. The corrosive atmosphere is created when oxygen and water mix, as the use of foaming agents requires the use of water and oxygen. Controlling corrosion can either be done mechanically or chemically. Mechanically by reducing oxygen concentrations through nitrogen producing units (NPU), however oxygen will still be present in hole thus its advised not solely depend on it. Chemical inhibition is a more reliable method of corrosion control. It can be achieved with different chemicals such as the use of amine film forming substances and phosphate ester anodic inhibitor (kippie, Bellinger \& Scott 2007). These are known to form a layer that protects metal surfaces. Caustic soda or lime can also be added for alkaline $\mathrm{pH}$ control. Nevertheless, only $70 \%$ to $75 \%$ efficiency has been achieved when such efforts are used in preventing corrosion. Use of unbroken plastic coatings can achieve total protection. Erosion also has higher chance in air/foam drilling than in conventional mud drilling. Drill cuttings traveling at high velocity in air can erode and thin drill pipe thickness. Evidence from air drilling activities shows that drill pipe erosion can take place between the tool joint metal and the hard band in cases where there is hard-banding of the box end. Such erosion affects the drill pipe's joint life span. If unattended to, wear on a drill string can lead to deviation problems as a result of changes in stabilization and bending characteristics and potential lost in hole scenario. Drilling engineers need to be diligent in identifying these corrosion hazards during pre-spud, ensuring constant monitoring during operation and proper post job visual inspection of tools (kippie, Bellinger\& Scott 2007).

Last but not least are downhole fires and explosions. Unfortunately, air drilling has the potential of meeting the three conditions required to start a fire, (1) Oxygen, (2) fuel and (3) ignition. The presence of hydrocarbons makes the use of air drilling technology to become hazardous but the main concern is to prevent ignition. Ignition while air drilling can happen either due to downhole sparks or due to a mud ring. A mud ring is a seal between bore hole and drill string created by drill cuttings and moisture. Mud rings are the main cause of downhole ignition. When a mud ring is formed, air circulation is stopped and gas continues to accumulate in a pressure chamber similar to the ignition chamber in a diesel engine (Copper, Hook \& Payne, 1977). As for the other source of ignition, there is little to no control against downhole sparks. The best measures against downhole sparks are to be geologically aware of formation being drilled as hard quartzite sands can cause sparks. Also, pay close attention to string vibration in order to avoid the drill pipe tool joint from striking the hard face of bore hole. Damage from downhole fire is usually limited to downhole equipment with little to no 
damage to surface equipment. However, damage from downhole makes fishing operations very challenging and a sidetrack become the most likely scenario.

There are certain operational procedures to be taken to prevent downhole explosions. If a gas who or an increase in standpipe pressure occur, immediately stop drilling and shut air off. Monitor gas flare and ascertain if gas is wet or not by checking smoke color (black smoke) and cuttings at sample catcher. If gas is wet, switch to mist drilling. If gas is dry, then resume drilling and ensure tool joints are free of mud rings by working string up and down. Monitor the standpipe pressure throughout the process as mud ring can occur quickly and only take a small amount of gas to cause an ignite (Copper, Hook \& Payne, 1977).

\section{Well CONTROL}

Drilling fluids can be designed be designed to be overbalanced (conventional) or underbalanced (unconventional). An overbalanced drilling fluid weight is planned to be above pore pressure to prevent flow from reservoir into wellbore while drilling. As such, it serves as the first barrier in case of well control issue. An underbalanced drilling fluid doesn't have sufficient weight, thus flow back is expected and countered by well control equipment. While flow back is expected in underbalanced drilling, an unexpected increase in flow (kick) can occur due to higher permeability or pressure than anticipated. Poor choke control while drilling can also cause a kick by lowering bottom hole pressure. Drilling with air/foam falls under underbalanced category and a proper understanding of required well control equipment is critical.

The first piece of equipment is the rotating control head. The rotating control head has a rubber element that seals around the DP to divert return flow away from rig floor and into the blooie line instead. The rubber element wears over time and it's not a good practice to run it to failure. It's a consumable item that needs to be checked and replaced routinely. When selecting a rotating control head, it's important to consider the DP stripping speed, length, rotating pressure and rotating hours. Another well control equipment is a float valve or non-return valve (NRV). NRVs allow one way flow only, from surface to downhole, and prevent hydrocarbons from traveling up the DP to surface. They are installed in the BHA and can be of different designs, flapper, ball, or dart. To mitigate risk of failure a backup NRV is installed in the DP (Ramalho\& Davidson, 2006). Figure 6 illustrates some of the well control equipment and safety valves setup in underbalanced drilling.

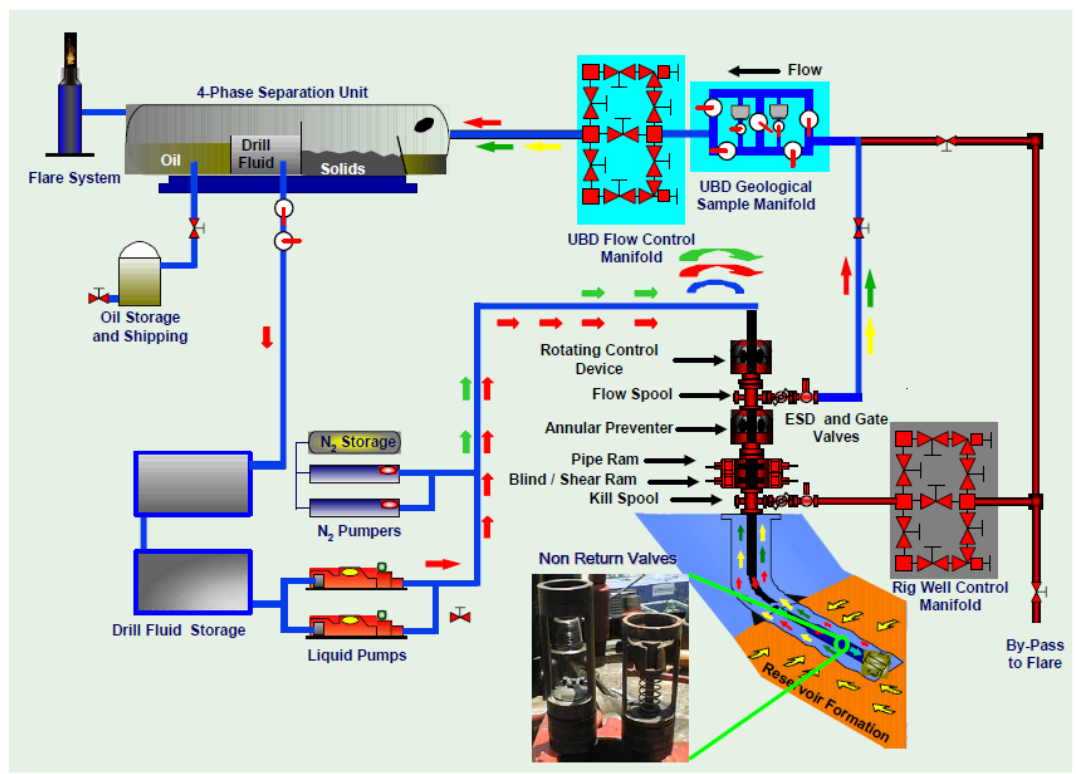

Figure6. Underbalanced drilling well control setup (courtesy of Ramalho\& Davidson 2006)

Well control practices in underbalanced drilling are quite the opposite to well control practices in overbalanced drilling. In underbalanced drilling, flow from formation is intentional while in overbalanced flow from formation is avoided. For example, in overbalanced drilling, drilling stops if gains occur and must be treated before leaving bottom. However, in underbalanced drilling the practice suggests continuing drilling during gains and leaving bottom if needed whilst well is flowing. As such, conventional well control training doesn't apply in cases of underbalanced drilling. 
Personnel working in underbalanced drilling operations must receive certified underbalanced well control training. A good underbalanced well control course would discuss the differences between overbalanced and underbalanced drilling regarding tripping operation, making connections and fluid weight control. It would cover rotating seals designs, wear factors, maintenance and inspection. Also explains choke control logic while drilling and available barriers and safety valves (Bourgoyne, 1997). Drilling with air/foam (underbalanced) is different but not unsafe. With the proper equipment and training, well control risk levels can be compared to drilling overbalanced.

\section{MAJOR PARAMETERS IN FOAM DRILLING OPERATIONS}

Despite the fact that the use of compressible fluids in drilling is gaining popularity, engineers are finding it more difficult to use foam than conventional fluids due to its stability properties and flow behavior. Unlike the mud traditionally used in drilling processes, the rheological and physical properties of foam are affected by changes in depth of wellbore. This has made it difficult to determine the best combination of drilling parameters.

There exist key drilling factors which can influence the circulating bottomhole pressure. Although some of these parameters can be controlled at the surface, some cannot be controlled by available mechanisms. Among the uncontrollable parameters is cuttings concentration. Theoretically, an increase in cuttings' concentration at the bottom creates a need for an increase in the injection rates, which can easily be done to offset this change. If there is equal nonconformity of pressure at the top and the bottom, it is concluded that there is a uniform increase in pressure in all the sections of the well. However, the need to increase the rate of injection increases as the depth increases. Increasing the velocity allows the operator to decrease the friction due to presence of laminar flow regime.

Cuttings size has been identified as another uncontrollable parameter. 0.4 inch is taken as the default cuttings diameter being increased by $50 \%$ and $100 \%$ to study the effects of this increase on flow characteristics and operational parameters at a steady back-pressure. In this case, an increase in pressure is not affected by changes in depth. At the same time, a difference between deviation at the top and deviation at the bottom of the well is an indication that the rate of change in injection rates is dependent on depth. As another uncontrollable parameter, formation water influx can be dealt with through a decrease in the liquid injection rate. The impact of water influx and required change in liquid injection rate to counter it decreases with depth. This is the mechanism used to avoid unwanted increase in the bottom hole pressure.

ROP is among the controllable parameters. In this regard, it is worth noting that the desired cuttings transport velocity is also dependent on the speed with which the cuttings are produced by the drill bit. An increase in the cuttings' terminal velocity can be achieved by increasing the ROP. An increase in ROP results in an increase in minimum required injection rate.Injection rates are also in the list of controllable parameters. Low injection rates should be avoided as they lead to pipe sticking and insufficient cuttings lifting capacity. Optimal injection rates are established to avoid high rates associated with washout problems and the need to purchase expensive pumps and compressors. Injection rate has the biggest influence on fluid velocity while ROP has the least. As the other controllable parameter, operators can create and control the necessary level of back-pressureusing a valve designed to work under the preferred range of conditions. Table 1, 2, 3, 4, \& 5 show the impact of each parameter (Paknejad, Schubert \& Amani, 2009).

Table1. Deviation of operational parameters and Flow characteristics for different cuttings concentrations

\begin{tabular}{|l|l|l|l|l|l|l|l|}
\hline \multicolumn{2}{|c|}{} & Pressure & $\begin{array}{l}\text { Gas Injection } \\
\text { Rate }\end{array}$ & $\begin{array}{l}\text { Liquid } \\
\text { Injection Rate }\end{array}$ & Velocity & $\begin{array}{l}\text { Moody } \\
\text { Friction }\end{array}$ & $\begin{array}{l}\text { Foam } \\
\text { Quality }\end{array}$ \\
\hline $\begin{array}{l}50 \% \text { increase } \\
\text { in } \\
\text { Concentration }\end{array}$ & $\begin{array}{l}\text { \% Deviation at } \\
\text { Top }\end{array}$ & 2.9 & 25.4 & 25.6 & 39.5 & $(44.5)$ & 0 \\
\cline { 2 - 8 } & $\begin{array}{l}\text { \% Deviation at } \\
\text { Bottom }\end{array}$ & 3.0 & 39.9 & 39.6 & 39.4 & $(43.6)$ & $(0.1)$ \\
\hline $\begin{array}{l}100 \% \\
\text { increase in } \\
\text { Concentration }\end{array}$ & $\begin{array}{l}\text { \% Deviation at } \\
\text { Top }\end{array}$ & 7.2 & 75.0 & 75.2 & 115.5 & $(74.3)$ & 0.0 \\
\cline { 2 - 8 } & $\begin{array}{l}\text { \% Deviation at } \\
\text { Bottom }\end{array}$ & 7.2 & 116.3 & 115.6 & 115.2 & $(73.4)$ & $(0.1)$ \\
\hline
\end{tabular}


A Comprehensive Overview of the Use of Compressible Drilling Fluids, Advantages and Challenges

Table2. Deviation of operational parameters and Flow characteristics for different cuttings Diameters

\begin{tabular}{|l|l|l|l|l|l|l|l|}
\hline \multicolumn{2}{|c|}{} & Pressure & $\begin{array}{l}\text { Gas Injection } \\
\text { Rate }\end{array}$ & $\begin{array}{l}\text { Liquid } \\
\text { Injection Rate }\end{array}$ & Velocity & $\begin{array}{l}\text { Moody } \\
\text { Friction }\end{array}$ & $\begin{array}{l}\text { Foam } \\
\text { Quality }\end{array}$ \\
\hline $\begin{array}{l}50 \% \text { increase } \\
\text { in } \\
\text { Concentration }\end{array}$ & $\begin{array}{l}\text { \% Deviation } \\
\text { at Top }\end{array}$ & 2.2 & 48.3 & 48.2 & 36.7 & $(42.4)$ & 0.0 \\
\cline { 2 - 8 } & $\begin{array}{l}\text { \% Deviation } \\
\text { at Bottom }\end{array}$ & 2.8 & 38.0 & 37.0 & 36.1 & $(41.4)$ & 0.2 \\
\hline $\begin{array}{l}100 \% \text { increase } \\
\text { in } \\
\text { Concentration }\end{array}$ & $\begin{array}{l}\text { \% Deviation } \\
\text { at Top }\end{array}$ & 5.1 & 102.3 & 101.8 & 76.0 & $(63.2)$ & 0.0 \\
\hline & $\begin{array}{l}\text { \% Deviation } \\
\text { at Bottom }\end{array}$ & 5.1 & 76.8 & 76.4 & 75.9 & $(62.2)$ & 0.0 \\
\hline
\end{tabular}

Table3. Deviation of operational parameters and Flow characteristics for different ROPS

\begin{tabular}{|l|l|l|l|l|l|l|l|}
\hline \multicolumn{2}{|c|}{} & Pressure & $\begin{array}{l}\text { Gas Injection } \\
\text { Rate }\end{array}$ & $\begin{array}{l}\text { Liquid } \\
\text { Injection Rate }\end{array}$ & Velocity & $\begin{array}{l}\text { Moody } \\
\text { Friction }\end{array}$ & $\begin{array}{l}\text { Foam } \\
\text { Quality }\end{array}$ \\
\hline $\begin{array}{l}50 \% \text { increase } \\
\text { in }\end{array}$ & $\begin{array}{l}\text { \% Deviation at } \\
\text { Cop }\end{array}$ & 1.4 & 9.3 & 9.3 & 15.6 & $(22.6)$ & 0.0 \\
\cline { 2 - 8 } & $\begin{array}{l}\text { \% Deviation at } \\
\text { Bottom }\end{array}$ & 1.2 & 15.4 & 15.6 & 15.6 & $(22.22)$ & 0.1 \\
\hline $\begin{array}{l}100 \% \\
\text { increase in } \\
\text { Concentration }\end{array}$ & $\begin{array}{l}\text { \% Deviation at } \\
\text { Top }\end{array}$ & 2.2 & 18.8 & 19.1 & 31.2 & $(38.2)$ & 0.0 \\
\cline { 2 - 8 } & $\begin{array}{l}\text { \% Deviation at } \\
\text { Bottom }\end{array}$ & 2.4 & 31.7 & 31.3 & 31.2 & $(37.4)$ & 0.1 \\
\hline
\end{tabular}

Table4. Deviation of operational parameters and Flow characteristics for different Injection rates

\begin{tabular}{|c|c|c|c|c|c|c|c|}
\hline & Pressure & $\begin{array}{l}\text { Gas Injection } \\
\text { Rate }\end{array}$ & $\begin{array}{l}\text { Liquid } \\
\text { Injection Rate }\end{array}$ & Velocity & $\begin{array}{l}\text { Moody } \\
\text { Friction }\end{array}$ & $\begin{array}{l}\text { Foam } \\
\text { Quality }\end{array}$ \\
\hline \multirow{2}{*}{$\begin{array}{l}50 \% \text { increase } \\
\text { in } \\
\text { Concentration }\end{array}$} & $\begin{array}{l}\% \text { Deviation } \\
\text { at Top }\end{array}$ & 0.3 & 50.7 & 50.0 & 49.8 & $(50.8)$ & 0.0 \\
\hline & $\begin{array}{l}\% \text { Deviation } \\
\text { at Bottom }\end{array}$ & 4.1 & 56.1 & 50.0 & 45.7 & (49.0) & 1.1 \\
\hline \multirow{2}{*}{$\begin{array}{l}100 \% \\
\text { increase in } \\
\text { Concentration }\end{array}$} & $\begin{array}{l}\% \text { Deviation } \\
\text { at Top }\end{array}$ & 0.6 & 101.9 & 100.0 & 99.4 & $(70.2)$ & 0.0 \\
\hline & $\begin{array}{l}\% \text { Deviation } \\
\text { at Bottom }\end{array}$ & 7.2 & 114.3 & 100.0 & 90.3 & (68.3) & 1.9 \\
\hline
\end{tabular}

Table5. Deviation of operational parameters and Flow characteristics for different Back-pressures

\begin{tabular}{|c|c|c|c|c|c|c|c|}
\hline & & Pressure & $\begin{array}{l}\text { Gas Injection } \\
\text { Rate }\end{array}$ & $\begin{array}{l}\text { Liquid Injection } \\
\text { Rate }\end{array}$ & Velocity & $\begin{array}{l}\text { Moody } \\
\text { Friction }\end{array}$ & $\begin{array}{l}\text { Foam } \\
\text { Quality }\end{array}$ \\
\hline \multirow{2}{*}{$\begin{array}{l}50 \% \text { increase } \\
\text { in } \\
\text { Concentration }\end{array}$} & $\begin{array}{l}\text { \% Deviation } \\
\text { at Top }\end{array}$ & 46.1 & $(27.0)$ & $(12.5)$ & (21.7) & 46.1 & 0.2 \\
\hline & $\begin{array}{l}\% \text { Deviation } \\
\text { at Bottom }\end{array}$ & $(12.1)$ & $(54.7)$ & (22.7) & 10.2 & 13.9 & 19.7 \\
\hline \multirow{2}{*}{$\begin{array}{l}100 \% \\
\text { increase in } \\
\text { Concentration }\end{array}$} & $\begin{array}{l}\% \text { Deviation } \\
\text { at Top }\end{array}$ & $(92.3)$ & $(29.5)$ & (14.7) & $(35.0)$ & 91.5 & 0.2 \\
\hline & $\begin{array}{l}\% \text { Deviation } \\
\text { at Bottom }\end{array}$ & (15.6) & $(73.1)$ & $(36.2)$ & 16.4 & 28.5 & 29.8 \\
\hline
\end{tabular}

\section{Air Drilling AND Well DeViation MEChanisms ANd CONTrols}

The use of air drilling is common in China in drilling zones of low permeability, formation with severe lost-circulation, areas with water shortage and formations that are water sensitive. The practices used for air drilling in China and other countries of the world show that controlling deviation in drilling is difficult and presents a critical problem than in cases of normal mud drilling. Well deviation in normal drilling is affected by many factors which can be grouped into two types, uncontrolled and controlled factors (Zhao, Gao\& Zheng, 2010). The factors that cannot be controlled consist of formation anisotropic index and formation dip. On the other hand, controllable factors are composed of RPM, WOB, BHA as well as drilling fluid properties among others. 
In terms of controllable factors, control of hole deviation can be achieved through adjustment of RPM, WOB or BHA. The optimization of these parameters can be established during the process of drilling in order to get the best outcome of deviation control (Zhao, Gao\& Zheng, 2010). Through various field practices it has been established that there is a great influence of the controllable factor in unplanned inclination of well bore. The prevention of hole deflection can be achieved through two types of BHA. These are packed and pendulum hole BHA. While pendulum assembly uses gravity in controlling the angle of the hole, the packed hole assembly makes use of stabilizers in forcing the bit to move straight along the planned direction of the hole (Zhao, Gao \& Zheng, 2010). A pendulum assembly is shown in figure 7A while packed hole assembly are represented by B and C. The single distinct feature between figure 7B and 7C is the large size of the diameter DCs that are in use in the assembly of $6 \mathrm{C}$ for enhancing the assembly's stiffness. In the actual practice of drilling, these three assemblies represented by A, B and C are not very effective for the control of deviation.
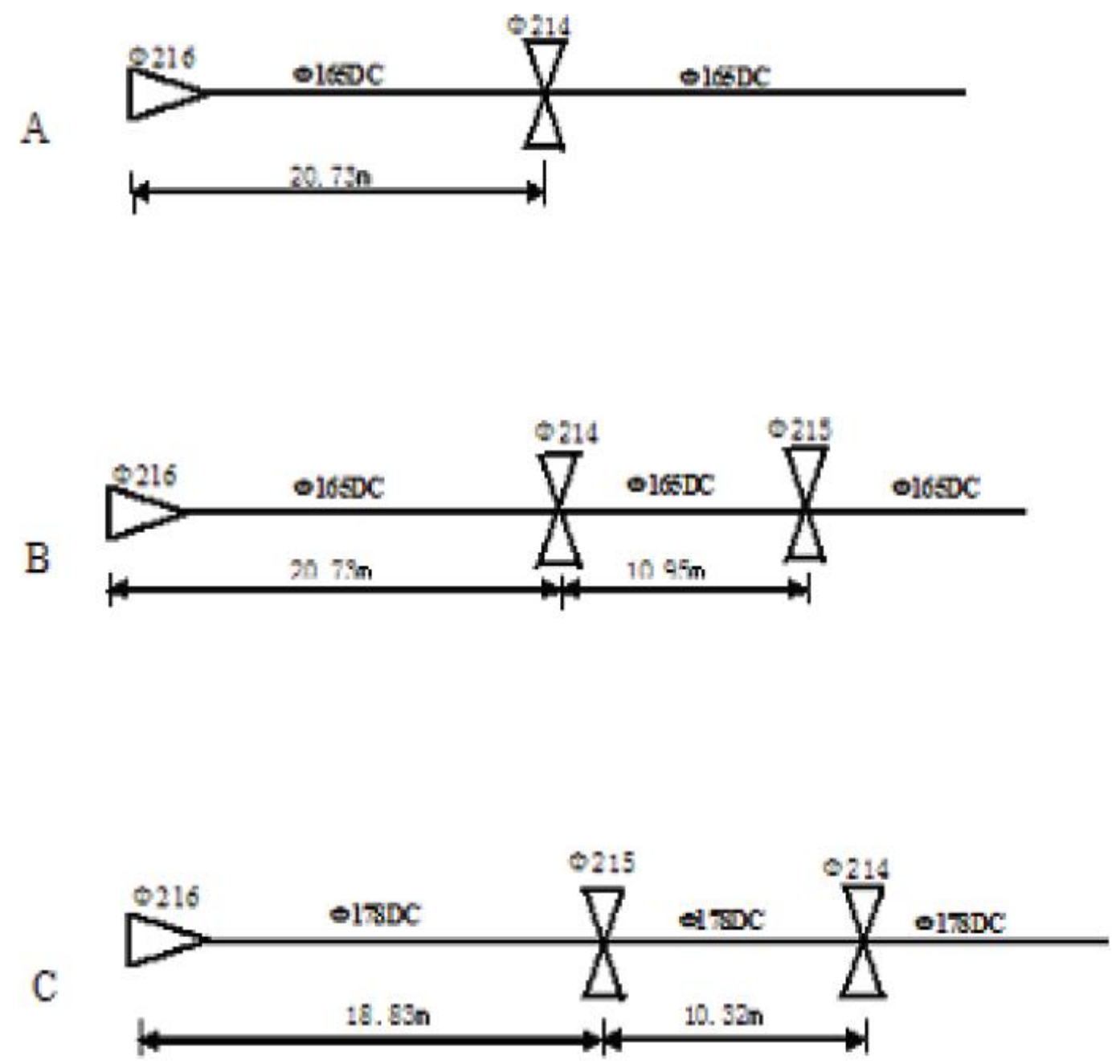

Figure7. Air drilling using different BHAs (Zhao, Gao\& Zheng, 2010)

From Figure 8, it is clear that there is a bigger difference in bit force assembly of A as compared to B and $\mathrm{C}$ at the same inclination and WOB while, on the other hand, it is similar to B and C assembly. The assembly of B portrays the maximum bit tilt angle in comparison to the assembly of B and C; however, there is a very small absolute value of the three assemblies. This justifies neglecting the impact that tilt angle of the bit may have on the overall deviation of the hole (Zhao, Gao \& Zheng, 2010).

Influence of stabilizer on deviation. In an effort to prevent well deviation, stabilizer has a wide use in drilling. In general terms, the clearance between the hole and the stabilizer and the positioning of the stabilizer have considerable sway on the mechanical features of bit. 
Figure 8 shows that, the positioning of the stabilizer is closely related to the mechanical characteristics of bit, while bit tilt angle will be rising, the bit side force will be declining. This shows that the tilt angle of the bit and side force of the bit is discord thereby a poor capability for deviation control. A comparison between mud drilling and air drilling reveals that both the tilt angle of the bit and the side force value of the bit in the case of air drilling is bigger in comparison to the case of mud drilling indicating that in air drilling there is a larger tendency in hole deviation (Zhao, Gao \& Zheng, 2010).
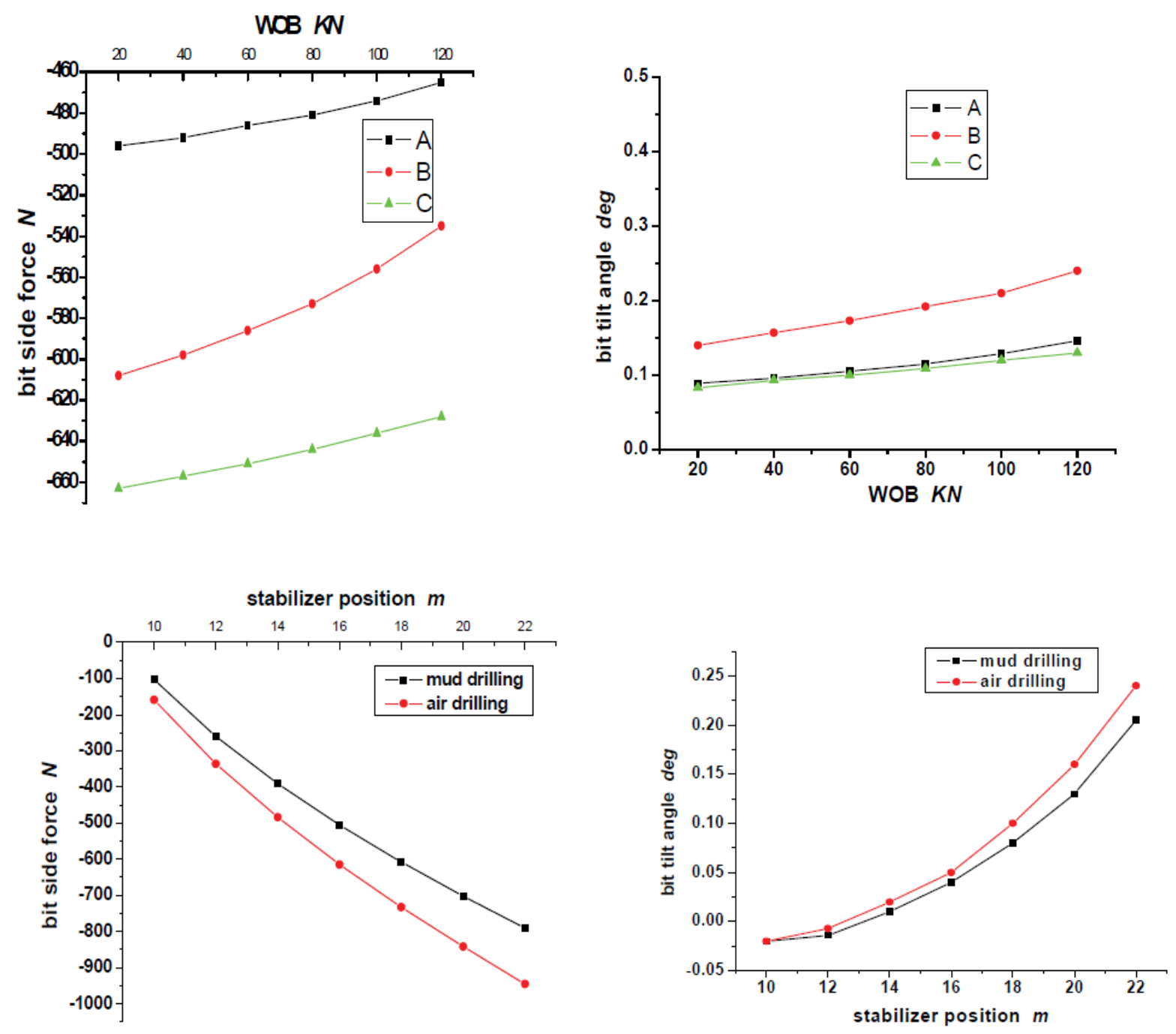

Figure8. Influence of the position of the stabilizer on tilt angle and side force of the bit (courtesy of Zhao, Gao\& Zheng, 2010)

The greatest significant disparity between mud and air drilling in this regard is the circulating medium. The fluid used in drilling has an effect on deformation, motion and loads of the drill string. According to figure 9, it is possible to conclude that tilt angle and side force of the bit are much greater in air drilling compared to mud drilling showing that there is a poor capability for controlling deviation of BHA that occurs in air drilling.

Impact of formation anisotropy. This constitutes the factors that cannot be controlled in an operation entailing air drilling, which varies due to lack of periphery pressure, which indicates that the force of formation natural deflecting in drilling with air is different from that of drilling with mud. The conditions of stress on both the rock on the bottom and on the wall takes a radical alteration. There is a tensile stress under the bottom while mud drilling shows a compression stress. The ability to drill of rocks varies significantly because of the difference in the hole rock stress at the bottom in mud drilling and air drilling (Zhao, Gao \& Zheng, 2010). 

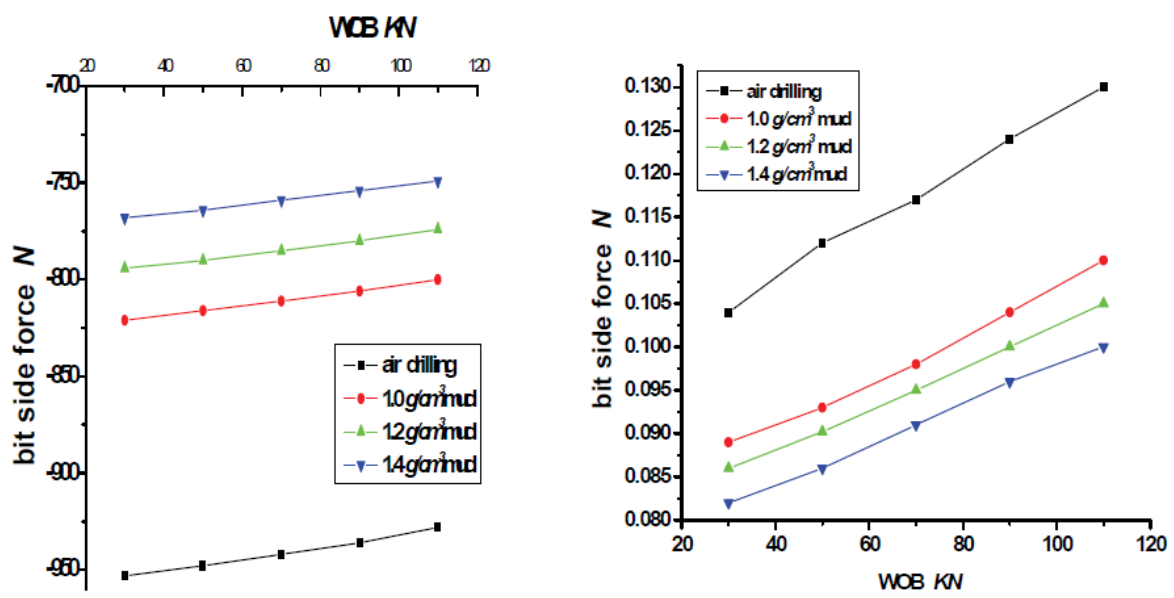

Figure9 - An association of tilt angle and side force of the bit in both mud and air drilling (courtesy of Zhao, Gao \& Zheng, 2010).

\section{EVOLUTION OF AIR DRILLING TECHNIQUES AND TECHNOLOGIES}

Air is regarded as the best fluid for use in underbalanced drilling, although it is known to prevent the use of mud pulse telemetry tools due to the absence of an incompressible fluid diminish the efficiencies of mud motors (Maranuk, Rodriguez, Trapasso\& Watson, 2014). It is for these reasons that oil is injected in small quantities to prevent corrosion in air drilling. Mud motors, electromagnetic telemetry and downhole air hammers are some of the common technologies employed in air drilling.

There has been increased use of EM MWD telemetry due to the advantages that it poses over the standard mud pulse telemetry systems. Firstly, EM MWD is preferred for the transmission of data from a tool downhole to the surface especially in underbalanced drilling. Secondly, it can be used with compressible fluids such as air and aerated fluids (Maranuk, Rodriguez, Trapasso\& Watson, 2014). However, the use of air poses a challenge to both in that it results in intense cross axial and axial levels of vibrations which are generated by the absence of liquid fluid regime.

The advancements towards air drilling were necessitated by several challenges faced in drilling operations. For example, bottomhole reservoir pressures were in most instances very low and this meant that the common weighted mud systems could not be employed. In the past, horizontal production wells were drilled by making use of positive displacement motors alongside EM LWD tools (Hartley, Weisbeck, Robert \& Smith, 2011). In several instances the use of steering motors resulted in wellbores that were tortuous. Recently the use of Rotary Steerable Systems (RSS) has been revealed to drill fewer winding laterals.

Originally, the basis of the EM MWD system was developed in the late 20th century and came into wide usage in the late 2000s. This system was in turn redesigned, enhanced and developed and various techniques incorporated as well as developed to facilitate the transmission lengthening of EM transmissions and the use of extended range transmitting antenna downhole. According to Hartley, Weisbeck, Robert \& Smith (2011) the use of insulated casing to reduce the attenuation of EM signal is another development that has taken place over the years. The length of deliver of transmission of data via EM has increased to depths of up to 20,000 feet, depending on the mud type and formation characteristics.

Tests commenced in 2002 to facilitate the integration of MPT M/LWD architecture with EM transmission. This led to the emergence of the HEL tool which could work under harsh conditions of high pressure, harsh temperatures and high vibrations. Compression algorithms for data to facilitate the conduction of greater data volumes have also been developed. These algorithms make use of LWD tools and MPT. For example, an efficient and improved EM telemetry can transmit triple the amount of data that was previously transmissible (Hartley, Weisbeck, Robert \& Smith, 2011).

Moreover, issues and challenges specific to EM transmission in dusting have been addressed. Example of problems addressed is the lack of attenuation of EM signals once the casing is set and when using fluids that do not conduct such as air (Hartley, Weisbeck, Robert \& Smith, 2011). This challenge is overcome by setting the surface casing high. 
The use of low frequency EM signals is a development that facilitates the transmission of data from downhole tools by enabling an equilibrium between transmission depth capability and the satisfactory rate of data transmission, which is usually 1 or 2 bits every second (Hartley, Weisbeck, Robert \& Smith, 2011). Two-way communication has also been developed to allow for down linking to the RSS and thus setting the deflection as well as the tool face.

The components of the RSS technology were initially engineered from a system that was tested in the field in 1994 (Hartley, Weisbeck, Robert \& Smith, 2011). Initially the RSS technology developed was planned to work by itself without any M/LWD system. RSS engineering developments saw an increase in size tools from $6 \frac{3 / 4}{4}$ in 2004 to $8 \frac{1 / 4}{4}$ in 2005 .

Newer versions of RSS have an in-built and improved seal assembly which enabling it to overcome differential pressure. This solves the problem of failure in earlier RSS configurations where failures were experienced, especially where there were clay swellings or ineffective cleaning of the hole as well as seal configuration being compromised resulting in induction of differential pressure. Computer based engineering models and laboratory testing drills have resulted in the modification of configuration of BHA and this translates to improvements in dogleg capability as well as predictability in directional performance (Hartley, Weisbeck, Robert \& Smith, 2011).

\section{CONCLUSION}

Air drilling has been a beneficial alternative to other applications. Use of air is one of the most preferred methods of drilling owing to the obvious advantages like cost and time effectiveness. It is preferred over mud drilling because of various reasons like the increase in the rate of penetration, elimination of lost circulation and minimal damages. The compressors used have changed over the years to become bigger and have bigger volumes and pressures. However, for an operator to optimize its advantages, should be aware of the challenges of air drilling. The equipment required in the air drilling are adversely reduced as compared to those used in mud drilling, which is an obvious advantage. To achieve the best conditions for air drilling it is important that hard and dry formations are used. Even with the obvious advantages of air drilling there are disadvantages that have been connected with the method. The use of out-of-gauge bits by operators can pose a challenge to air drilling. As earlier stated, the operator needs to know how to optimize on the method to make the best of it. Operators should, therefore, avoid starting drilling immediately after the drill hits the bottom as this will help avoid any hole deviations which can pose a major problem during drilling.

Understanding the major parameters in drilling operations is important. The best combination of drilling parameters may be difficult to determine and thus, understanding those will be an important factor for an operator. Parameters like cutting concentrations and cutting size are some of the uncontrollable parameters and therefore, operators need to be keen about how they control them. Air drilling is not best suited for all areas. Areas with low permeability and with water shortages are some of the areas that are best for air drilling. Factors that affect drilling can either be uncontrolled or controlled factors. Optimization of particular parameters such as the adjustment of RPM and BHA can help in getting the best deviation outcome. Stabilizers can also be used to prevent well deviations. When a well is properly prevented from deviation the end outcomes are usually the best. There have been developments in the world of air drilling and it continues to grow. The development of EMWD has enabled the sending of airwaves to the surface. The use of the equipment has however, come under scrutiny noting that it might bring to the surface the required information. However, these issues have been addressed and they continue to be improved so that it can be optimized. With the increased technology, more wells will be drilled using this method and the outcomes will continue being positive.

\section{NOMENCLATURE}

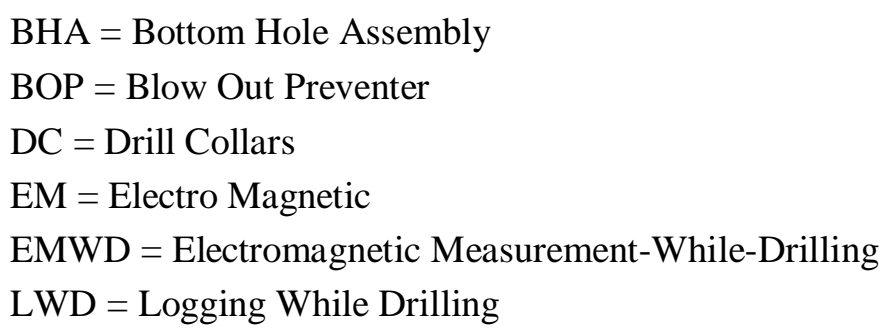




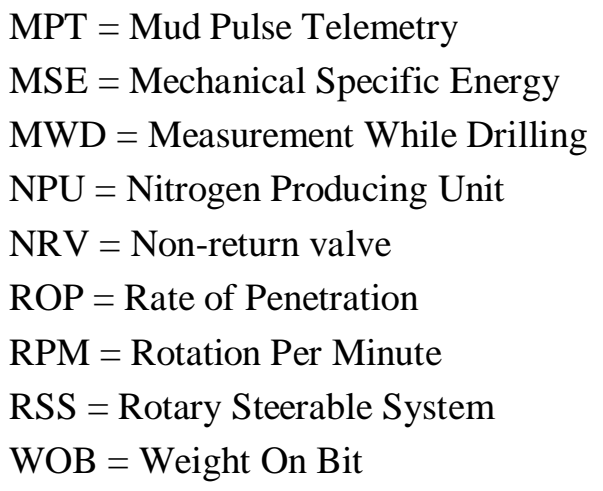

\section{REFERENCES}

[1] Gilbert, T.J. \& Tucker B.D. (1968). “Air drilling to date 1952-1968." $19^{\text {th }}$ annual technical meeting of Petroleum society of CIM in Calgary, Canada, 7-10 May 1968.

[2] Copper, L.W., Hook, R.A. \& Payne, B.R. (1977). “Air Drilling Techniques.” Deep drilling and production symposium of SPE in Amarillo, Texas, 17-19 April 1977.

[3] Ramalho, J. \& Davidson, I. (2006). "Well-Control Aspects of Underbalanced Drilling Operations." IADC/SPE Asia Pacific Drilling Technology conference and exhibition, Bangkok, Thailand, 13-15 November 2006.

[4] Bourgoyne, A.T. (1997). "Well Control Considerations for Underbalanced Drilling." SPE Annual Technical conference and exhibition, San Antonio, Texas, 5-8 October 1997.

[5] Paknejad, A., Schubert, J. \& Amani, M. (2009). “Key Parameters in Foam Drilling Operations.” SPE Managed pressure drilling and underbalanced operations conference and exhibition in San Antonio, Texas, 12-13 February 2009.

[6] Hartley, C,,Weisbeck, D., Robert, S. \& Smith, M. (2011). "The Successful Evolution of LWD Rotary Steering System for Air Drilling." SPE/IADC Drilling Conference and Exhibition in Amsterdam, Netherlands, 1-3 March 2011.

[7] Maranuk, C., Rodriguez, A., Trapasso, J. \& Watson, J. (2014). “Unique systems for the underbalanced drilling using air in Marcellus Shale.” SPE Eastern Regional Meeting in Charleston, West Virginia, 21-23 October 2014.

[8] Zhao, Z., Gao, D. \& Zheng, D. (2010). “Mechanism of well deviation in air drilling and its control.” SPE international Oil \& Gas Conference and Exhibition in Beijing, China, 8-10 June 2010.

[9] Meng, Y., Wan, L., \& Chen, X. (2005). "Discussion of foam corrosion inhibition in air foam drilling." SPE international symposium on Oilfield corrosion in Aberdeen, UK, 13 May 2005.

[10] Hongjun, Z., Yuanhua, L., \&Yinfeng, M. (2010). "Influence of relevant parameters on hole cleaning in air drilling." SPE oil and gas india conference and exhibition in Mumbai, India, 20-22 January 2010.

[11] Kippie, D., Bellinger, C., \& Scott, P. (2007). “Combining a mechanical and chemical solution to mitigate corrosion in MPD/UBD/Air drilling operations. " IADC/SPE managed pressure drilling and underbalanced operations conference and exhibition in Galveston, Texas, 28-29 March 2007.

[12] Bybee, K. (2007). “Air Drilling in the Presence of Hydrocarbons: A Time for Pause."Journal of Petroleum Technology. Issue of November 2007.

[13] Nas, S., Gala, D., \& Cox, P. (2010). "Deep air drilling application to enhance rate of penetration in extremely hard, abrasive and high temperature environment." SPE Engineers - International Oil and Gas conference and exhibition in Beijing, China, 9-10 June 2010

Citation: Mahmood Amani, and Mohamed Almodaris (2017). A Comprehensive Overview of the Use of Compressible Drilling Fluids, Advantages and Challenges, International Journal of Petroleum and Petrochemical Engineering (IJPPE), 3(4), pp.19-31, DOI: http://dx.doi.org/10.20431/2454-7980.0304002

Copyright: (C) 2017 Mahmood Amani, and Mohamed Almodaris. This is an open-access article distributed under the terms of the Creative Commons Attribution License, which permits unrestricted use, distribution, and reproduction in any medium, provided the original author and source are credited 